This is the peer reviewed version of the following article: McBride E, Hacking B, O'Carroll R, Young M, Jahr J, Borthwick C, Callander A \& Berrada Z (2016) Increasing Patient Involvement in the Diabetic Foot Pathway: A Pilot Randomised Controlled Trial, Diabetic

Medicine, 33 (11), pp. 1483-1492, which has been published in final form at http://doi.org/10.1111/dme.13158. This article may be used for non-commercial purposes in accordance With Wiley Terms and Conditions for self-archiving. 


\section{Increasing Patient Involvement in the Diabetic Foot Pathway: A Pilot Randomised Controlled Trial}

Emily McBride*, CPsychol, NHS Lothian.

Belinda Hacking, ClinDoc, NHS Lothian.

Ronan O’Carroll, PhD, University of Stirling.

Matthew Young, ClinPhD, NHS Lothian.

Jessica Jahr, MA(Hons), NHS Lothian.

Claire Borthwick, MA(Hons), NHS Lothian.

Alana Callander, MSc, NHS Lothian.

Zaynab Berrada, NHS Lothian.

* Corresponding author Emily McBride : 2-4 Waterloo Place, Waverley Gate, Public Health, NHS

Lothian, Scotland, UK, EH1 3EG at time of study. Now contactable at e.mcbride@ucl.ac.uk

- To our knowledge, this is the first study to test an intervention to facilitate shared decision making in this population.

- Despite the national push for shared decision making in diabetes, this pilot study found no impact on patient confidence or adherence.

- Patients were more conflicted about decisions after increased involvement in the care pathway.

- Unexpectedly, we observed extremely high decisional confidence at baseline. This would appear to be in conflict with high morbidity and mortality rates.

- This extremely high confidence may be indicative of little perceived need to engage in treatment pathways. This has important practice implications for future interventions. 


\begin{abstract}
Aims: This pilot study aimed to explore whether the use of an intervention to increase shared decision making (Decision Navigation) in patients with a diabetic foot ulcer increased: (i) decision self-efficacy and (ii) foot treatment adherence.

Methods: Fifty six patients with a diabetic foot ulcer were randomised to receive Decision Navigation $(N=30)$ or usual care $(N=26)$. Primary outcomes included decision selfefficacy, adherence to foot treatment as reported by the patient and adherence to foot treatment as reported by the clinician. Secondary outcomes included foot ulcer healing rate, health-related quality of life, decisional conflict and decision regret.

Results: Despite patients' rating DN as very helpful, mixed ANOVAs revealed no differences in decision self-efficacy or adherence between those receiving DN and usual care. There were no differences between groups with regards to the secondary outcomes, with the exception of decision conflict which increased over time (12 weeks) for those receiving DN.

Conclusions: An intervention which facilitated patient involvement in treatment decisions did not have any impact on decisional confidence or adherence to foot treatment. This does not provide support for the suggestion that personalised care can improve health-related outcomes at this progressed stage of the patient's disease trajectory. We suggest that the diabetic foot population may benefit from interventions at any earlier stage following diagnosis aimed at increasing motivation to engage with care pathways, centred on challenging personal controllability beliefs.
\end{abstract}


Diabetic foot ulceration predicts a five year mortality of up to $55 \%$ from ulcer onset and up to 74\% post lower-leg amputation (1). National guidelines have directed towards a multidisciplinary approach in diabetic foot care with emphasis on the integration of psychological focus $(2,3)$. Shared decision-making between the healthcare professional and patient is currently poor in this population. Increased patient involvement in treatment decisions may improve health outcomes through improved quality of care and increased treatment adherence (4).

\section{Foot self-care and adherence to treatment}

The recovery trajectory of a diabetic foot ulcer is largely dependent on foot self-care behaviours and adherence to treatment regimens. On average, a diabetic foot ulcer takes 133 days to heal (5). Those who do not adhere well to foot treatment may obtain a chronic ulcer and/or one which may worsen to the point of amputation. It has therefore been widely acknowledged that promoting patient engagement with treatments and self-care behaviours is central to improving health and clinical outcomes in this population (6).

Over the past decade, the importance of psychological factors in predicting adherence and self-care behaviours has been recognised in diabetic foot research (7). Tailored interventions, personalised in line with patient's treatment agenda and beliefs, must play an important role in improving these outcomes $(8,9)$.

\section{Decision Navigation}

'Decision navigation' (DN) is a multi-component intervention designed to facilitate shared decision-making between a healthcare professional and patient in practice. It is built on techniques which have been shown to increase patient involvement in question asking and improve information recall $(10,11)$.

The main component of DN takes the form of an interview between the patient and a trained 'Navigator' in order to form a consultation plan (written summary) of the patients' questions/concerns relating to their care and treatment. This consultation plan is then used 
within a routine appointment as an agenda with a healthcare professional. Audio recordings and a written document of the information discussed are generated and given to the patient.

DN has previously been shown to enhance decisional confidence and certainty, as well as reduce decisional regret, in newly diagnosed prostate cancer patients faced with treatment choices (12). This intervention has traditionally been used with different groups of cancer patients (see www.SCOPED.org for further details). To our knowledge, DN had never been tested or implemented in patients with chronic conditions.

\section{The Current Study}

As highlighted previously, patients with a diabetic foot ulcer experience some of the poorest morbidity and mortality outcomes recorded in chronic illness (4). These patients are also faced with treatment decisions which often require increased urgency with measurable impact relative to the general diabetes population. For example, patients with a diabetic foot ulcer may need to make explicit treatment decisions surrounding amputation, plaster cast vs. specialist foot device or infection control methods. They may also need to make decisions which relate to quality of life vs. healing rate, e.g. the decision to take time out of employment/change employment in order to rest their foot and prevent future ulcers. To our knowledge, there has been no published research to date which tests shared decision making in the diabetic foot population.

This pilot study primarily aimed to test whether the use of an intervention to facilitate shared decision-making (Decision Navigation) increased (a) decision self-efficacy and (b) adherence to foot treatment in patients with a diabetic foot ulcer. 


\section{Methodology}

\section{Participants}

Participants were recruited from a single-site diabetes foot clinic in the Edinburgh Royal Infirmary, UK between 01/07/14 and 31/03/15.

Patients who were newly diagnosed with a diabetic foot ulcer and/or considering a new treatment (as identified by a Consultant Clinician) and who did not display the normal anticipated healing rate were eligible. This was defined as $\leq 30 \%$ improvement in ulcer healing rate two weeks post initial contact with the diabetes foot clinic. Patients with any type of diabetes were eligible. Given a key aim of shared decision making is to promote personalised care, patients could be enrolled into other clinical studies trialling foot treatments (e.g. dressing treatment) as long as these formed part of their normal treatment decisions within the clinic.

Patients were excluded who were: unable to give informed consent; displayed a severe ischemic foot ulcer; had an identifiable severe psychiatric morbidity; and/or were younger than 16 years old.

\section{Design}

This pilot study took the form of a randomised controlled trial testing the Decision Navigation intervention relative to usual care.

\section{Randomisation}

Group allocation sequence was determined by an external researcher through the use of a computerised generated random number table (www.randomizer.org). To ensure allocation concealment from the research team and participants, opaque, sealed envelopes were employed which contained a note of group allocation. Envelopes were opened by a member of the research team after baseline measures had been taken and group allocation was then 
communicated to patients and the foot team. Due to the interactive nature of the intervention it was not possible for group allocation to be blinded.

\section{Procedures}

Ethical approval was obtained from the NHS South East Scotland Research Ethics Committee (ref 14/SS/0057).

Patient eligibility was assessed by a consultant diabetes clinician. All patients were approached by a consultant clinician or podiatrist who introduced the study. Patients were given an information pack to take away and read if they stated that they were interested in participating.

At follow-up appointment in the foot clinic approximately 2 weeks later, a consultant clinician or podiatrist asked the patient whether they would like to participate. If the patient agreed, they were then introduced to the research team who took informed consent confirmed through written signature and baseline measures in person. Wherever possible, participants completed follow-up questionnaires as part of their attendance at the foot clinic. Some participants who had been discharged completed the 12 week follow-up questionnaires at home and returned them via postal mail. Ulcer measurements were taken as part of routine care and communicated to the research team by podiatrists.

\section{Control (Usual care)}

Patients allocated to the control group received standard care. This pathway typically took the following structure: (i) formal assessment of ulcer; (ii) treatment plan formed, most frequently incorporating the use of debridement, off-loading, infection control, and/or a vascular intervention; (iii) patient received treatment advice; and (iv) patient attended clinic at regular intervals for check-ups as advised by the clinician.

\section{Intervention (Decision Navigation)}

Patients in the intervention group received standard care along with Decision Navigation, which is a multi-component intervention developed to promote informed treatment decision 
making (Table 1). Decision Navigation was delivered to patients by a trainee health psychologist and four assistant psychologists, who were formally trained in the methods by the founder of the intervention (Jeff Belkora). The training consisted of a two day course and weekly case reviews for a period of two months. Fidelity tests on the Navigated documents were also carried out by the founder of the methods for 5 months. Healthcare professionals were not trained in the methods; however the purpose of this intervention was to be feasible for implementation in routine practice and so Navigators were trained to provide assistance in facilitating the use of consultation plans between healthcare staff and patients where necessary.

\section{Descriptive Measures}

Measures of gender, age, ethnicity, marital status, education and employment were taken at baseline (table 1). Patient status was categorised as: (i) New Patient (ii) Reulcered Patient or (iii) Current Patient. New patients were defined as those who had entered the foot clinic for the first time; reulcered patients had been newly referred to the clinic for a second time or more; and current patients were those receiving ongoing foot treatment with a new decision to make. Time (days) between recruitment and exit from the study was calculated.

\section{Outcome Measures}

Table 2 provides an overview of measures, time points and example questions for all scales used in this study.

Baseline is defined as immediately after recruitment but prior to group allocation. T1 is defined as during the next appointment at the foot clinic (approximately two weeks after recruitment). T2 is defined as 12-weeks post appointment.

Decisional self-efficacy (DSE) (13), adherence to treatment as reported by the patient and adherence to treatment as reported by the clinician were our primary outcome measures. These were all measured at baseline and T2. DSE was additionally measured at T1.

We chose three primary outcomes as we were interested in whether changing decision selfefficacy would lead to a change in both clinician and patient rated adherence. In this 
exploratory study we did not apply a weighting, however in a future study, as decision selfefficacy is being targeted by the intervention, this variable should be used as the basis of the power calculation.

Decision conflict (DC) (14), decision regret (DR) (15), wound healing rate, health-related quality of life (HR-QoL) (16) and patient acceptability of DN were our secondary outcome measures. Ulcer size and HR-QoL were measured at baseline and T2. DC was measured at T1 and T2. Patient acceptability (only measured intervention group) and DR were measured at T2 only.

\section{Statistical Analyses}

Data was coded and analysed using SPSS version 21, 2012.

The key test of the primary hypotheses was whether the change over time differed between the groups, tested via a group by time interaction in the ANOVA for all primary outcome measures.

Given that this was a pilot study, a key aim was to calculate effect sizes which could inform the justification and/or design of a larger trial. The sample size for this pilot was determined by practical considerations which centred on the recruitment time-frame available.

\section{Missing data}

The main analyses were conducted twice using both completer analysis and intention to treat analysis. In completer analysis, numbers analysed were reported for each outcome. Intentionto-treat analysis was also conducted and reported separately, whereby baseline (last) scores were carried forward and entered in place of missing data for repeated measures (17). 


\section{Results}

Patients with a diabetic foot ulcer were randomly allocated to receive the additional service 'Decision Navigation' $(N=30)$ or to receive usual care $(N=26)$.

\section{Demographics and Baseline Characteristics}

One hundred six individuals were invited to take part in the study; fifty-six consented and were randomised to the intervention or control group. Fifty-six data sets were analysed at T1 and forty-nine data sets were analysed at T2 (seven lost to follow-up). See Figure 1.

One-way ANOVA and Chi-square analyses revealed no significant differences between the intervention and control with regards to any descriptive measures (see Table 3). On this basis, no descriptive variables were entered as covariates in subsequent analyses. Baseline characteristics were also similar, with no significant differences yielded between groups.

Time in the study did not significantly differ between control ( $M=99$ days, $S D=21.6)$ and intervention ( $M=97.6$ days, $S D=19.4), F(1,48)=.06, p=.815$.

The lack of differences between the intervention and control in demographics and baseline characteristics indicates that the randomisation process was effective.

\section{Primary outcomes}

A summary of the full statistical results is presented in Table 4.

Mixed ANOVAs revealed non-significant group x time interactions for decision self-efficacy, $p=.299, \eta p^{2}=.026$, adherence as reported by the patient, $p=.934, \eta p^{2}=<.001$, and adherence as reported by the clinician $p=.934 \eta p^{2}=<.001$.

\section{Secondary outcomes}

A two-way mixed ANOVA (two time points) revealed a significant group $\mathrm{x}$ time interaction for decision conflict, $p=.049, \eta p^{2}=.077$. Post-hoc comparisons revealed that DC increased 
from $17.1 \%$ at $\mathrm{T} 1$ to $23.27 \%$ at $\mathrm{T} 2$ in the group receiving $\mathrm{DN}, p=.042$. No significant decrease in DC over time was observed in those receiving usual care.

A mixed ANOVA (two time points) revealed a non-significant group $\mathrm{x}$ time interaction for health-related quality of life, $p=.409, \eta p^{2}=.015$.

Between subjects ANOVAs revealed no significant differences for wound healing rate (difference in ulcer size over time), $p=.461, \eta p^{2}=.013$, or decision regret, $p=.625, \eta p^{2}=.005$.

Mean scores on each facet of patient acceptability of $\mathrm{DN}(N=25)$ revealed that participants receiving DN rated the helpfulness of the treatment decision aid 8.4, the interview with a Navigator as 8.39, the audio recording of their consultation as 8.32 and the written summary as 8.75. Overall DN was rated as 8.32 for helpfulness. All means were scored out of 10 . $100 \%$ of participants reported that they would opt into using DN again and 100\% reported they would recommend it to another diabetic foot patient.

\section{Intention-to-treat analysis (ITT)}

All primary and secondary outcomes were additionally analysed based on the initial treatment assignment. ITT analyses were consistent with the main completer analyses; there were no differences in the conclusions drawn. See Table 5 for ITT results. 


\section{Discussion}

The way in which Decision Navigation (DN) was implemented in patients with a diabetic foot ulcer was rated as acceptable and helpful. However, this yielded no statistically or practically significant differences with regards to decisional confidence or adherence to foot treatment. Although UK national guidance has pushed for increased patient involvement in treatment care pathways in this population (18), the results of this pilot study suggest that an intervention aimed at facilitating shared decision-making is not likely to impact patient foot behaviours at this progressed stage in the disease trajectory.

Based on the extremely high existing decisional confidence observed in this study, we make the case that the diabetic foot population may benefit more from interventions focussed on building motivation to engage with treatment care pathways in the first instance, centred on challenging personal controllability beliefs, rather than the most commonly utilised approach to date of educational interventions aimed at improving confidence and treatment knowledge (19).

\section{Decision-making outcomes}

Based on psychological theories of behaviour it seemed logical to hypothesise that patient decision self-efficacy would be low at baseline due to the poor adherence and high mortality outcomes in the diabetic foot population $(20,21)$. Traditionally, low self-efficacy predicts poor performance of behaviours (22). However, this study found that patients with a diabetic foot ulcer displayed a very high mean decision self-efficacy score of $83.5 \%$ at baseline. This would appear to be in conflict with the poor adherence and poor health outcomes observed in this population, which therefore presents the diabetic foot ulcer population as a more unusual case. These individuals appeared to be extremely confident in their ability to source information relevant to their treatment and care; however the objective figures from research imply that their actions do not reflect this. The very high decision self-efficacy observed in this study could help to explain why the findings differed from previous research where the same DN intervention was shown to increase decision self-efficacy in prostate cancer patients (12). It is possible that patients with a diabetic foot ulcer may have perceived little need to engage in the treatment decision-making process via very high existing confidence that their decisions and involvement in foot care pathways were adequate. 
This is an important consideration as to date most diabetic foot research has developed educational interventions and materials with the aim of increasing knowledge and patient confidence in relation to the self-care for their foot. However, the findings of this study instead suggest that interventions aimed at increasing motivation to engage in treatment pathways, rather than building self-efficacy and knowledge around them, may be more helpful for this population. It could also help explain why behaviour change attempts using this approach in this population to date have not been fruitful (19). It is important that future interventions are tailored and tested in line with this information.

A further point which supports this notion is, whereas the Hacking et al (12) study found that DN reduced decisional conflict, this study found that the DN intervention significantly increased decisional conflict over time (12 week period). In other words, this intervention resulted in patients who were more conflicted despite the aim of easing the decision process. This is particularly interesting given this is inconsistent with what would be expected when implementing an intervention to facilitate shared decision making.

In an attempt to make sense of this finding, we speculate that this population may have displayed a "low internal health locus of control"; this has also been suggested in previous diabetic foot research (23). This psychological term is used to describe a set of characteristics whereby an individual may believe that there is little that they can personally control in their care/recovery pathway (e.g. self-care at home) and may place far heavier weighting on external factors (e.g. health services/professionals). This could present a profile of a group who have had a long term condition for some time and may attend and/or over-engage in health service appointments, yet do not appear to recover as would be expected due to a lack of adherence to prescribed treatment and/or self-care behaviours. In the context of the increased decision conflict over time as a result of $\mathrm{DN}$, the action of prompting this patient group to independently consider their personal treatment options may have created the perception of choices where there were none previously; i.e. the intervention may have increased decisional conflict via challenging personal controllability beliefs. For example, the belief that treatment decisions lay fully with the healthcare team may have been challenged via the intervention actively presenting that treatment decisions were negated by the patient through use of the question list. In line with this view, the increased decisional conflict observed may have been a result of patients engaging in a learning process. These 
mechanisms are, however, hypothetical as the study methodology was not designed to detect controllability beliefs and there is not currently enough psychological literature in this population to draw from. We recommend that future studies should incorporate measures of controllability beliefs and include patients who have recently been diagnosed as well as those who have more advanced conditions(25).

\section{Behavioural and clinical outcomes}

This pilot study found no evidence to support DN as a method for improving adherence to treatment or wound healing.

In order for these outcomes to have improved, it was hypothesised that DN would need to have (i) increased decision self-efficacy to promote a direct link with patient treatment engagement and/or (ii) corrected illness or treatment misconceptions via personalised education from the healthcare team $(22,24)$. Given that DN had no impact on decision selfefficacy, then it is no surprise that adherence to treatment did not differ.

\section{Limitations}

The DN intervention is a facilitative method and thus no direct information was offered by the Navigators delivering it. The effectiveness of DN was therefore largely dependent on the clinicians' and patients' engagement with it. No training was provided to the healthcare team involved in this project with regards to delivery of shared care and/or behaviour change. In order to maximise the likelihood of reaching behavioural outcomes, it would be useful for future studies adopting interventions which present with the opportunity for behaviour modification to provide training to those involved in relevant methods, e.g. Motivational Interviewing (26).

It is also worth noting that within the patient and clinician-reported adherence questionnaires, the five facets of the foot treatments were equally weighted in the scoring procedures. However, it is likely that certain treatments, such as antibiotics, required higher weighting due to increased patient self-monitoring and larger clinical effects on health outcomes. The patient adherence measure developed for this study yielded a low alpha-coefficient of 0.43. 
This highlights the need for development of a validated and reliable tool for measuring adherence in this population.

It is also possible that there were ceiling effects with regards to the primary outcome measures. DSE and adherence to treatment measures were all $>80 \%$ at baseline meaning that increases would have been difficult. These difficulties in detecting differences would have been amplified as this pilot study had a small sample size and thus was underpowered.

This study was also limited to one site in the Royal Infirmary of Edinburgh, which performed well in national audits on clinical outcomes. The sample also consisted of 100\% white British participants and was limited to those who agreed to participate. This limits the degree to which the finding can be generalised to the diabetic foot population. The individuals and healthcare teams who may benefit most from this type of intervention may not have been captured through the sample yielded in this study. The small sample size also limits the representativeness of the findings to the wider diabetic foot population.

\section{Sample Size}

A key aim of this pilot study was to justify and/or inform the design of a larger trial. Based on the very small effect sizes observed across all outcomes, we think it is is unlikely that this intervention would yield clinically meaningful treatment effects in a subsequent large adequately powered trial. We suggest that future interventions aimed at increasing motivation to engage in treatment pathways are worthy of further evaluation in this population.

\section{Acknowledgements}

We would like to thank the staff in the diabetic foot department in the Edinburgh Royal Infirmary for dedicating some of their valuable time to recruiting participants and implementing this study. We would also like to thank Jeff Belkora for contributing his time and input to staff training in Decision Navigation. Finally, we would like to thank those individuals attending the foot clinic who agreed to participate in this trial. 


\section{Author Contributions:}

Study concept and design: Hacking, McBride, O’Carroll, Young.

Acquisition of data: Beradda, Borthwick, Callander, Jahr, McBride, Young.

Analysis and interpretation of data: McBride, O’Carroll.

Writing of manuscript: McBride.

Contribution to discussion: Beradda, Borthwick, Callander, Hacking, Jahr, McBride, O’Carroll, Young.

Administrative support: Beradda, Borthwick, Callander, Jahr.

\section{Funding:}

This work was supported by NHS Lothian and NHS Education for Scotland.

\section{Conflicts of interest:}

The authors have no conflicts of interest to declare. 


\section{References}

1. Schofield CJ, Libby G, Brennan GM, MacAlpine RR, Morris AD, Leese GP. Mortality and hospitalization in patients after amputation: a comparison between patients with and without diabetes. Diabetes Care 2006;29:2252-6

2. Robbins JM, Strauss G, Aron D, Long J, Kuba J, Kaplan Y. Mortality rates and diabetic foot ulcers: is it time to communicate mortality risk to patients with diabetic foot ulceration? Journal of the American Podiatric Medical Association 2008;98:489-93

3. National Institute for Health Care and Excellence. Diabetes in adults quality standard: Quality statement 3- Care planning, 2011. Available from: http://publications.nice.org.uk/diabetes-in-adults-quality-standard-qs6/quality-statement3-care-planning. Accessed 10 February 2014

4. Montori V, Gafni A, Charles C. A shared treatment decision-making approach between patients with chronic conditions and their clinicians: the case of diabetes. Health Expectations 2006;9:25-36

5. Zimny S, Schatz H, Pfhol M. Determinants and estimation of healing times in diabetic foot ulcers. Journal of diabetes and its complications 2002;16:327-32

6. McInnes A, Jeffcoate W, Vileikyte L, Game F, Lucas K, Higson N, Stuart L, Church A, Scanlan J, Anders J. Foot care education in patients with diabetes at low risk of complications: a consensus statement. Diabetic Medicine 2011;28:162-7

7. Vedhara K, Dawe K, Wetherell M, Miles J, Cullum N, Dayan C, Drake N, Price P, Tarlton J, Weinman J, Path A, Campbell R. Illness Beliefs Predict Self-Care Behaviours in Patients with Diabetic Foot Ulcers: A Prospective Study. Diabetes Research and Clinical Practice 2014;106:67-72

8. Chin YF, Huang TT, Hsu BR. Impact of action cues, self-efficacy and perceived barriers on daily foot exam practice in type 2 diabetes mellitus patients with peripheral neuropathy. Journal of Clinical Nursing 2013;22:61-8 
9. Vileikyte L, Gonzalez JS, Leventhal H, Peyrot MF, Rubin RR, Garrow A, Ulbrecht JS, Cavanagh PR, Boulton AJ. Patient Interpretation of Neuropathy (PIN) questionnaire: an instrument for assessment of cognitive and emotional factors associated with foot selfcare. Diabetes Care 2006;29:2617-24

10. Kinnersley P, Edwards A, Hood K, Cadbury N, Ryan R, Prout H, Owen D, Macbeth F, Butow P, Butler C. Interventions before consultations for helping patients address their information needs. The Cochrane Database of Systematic Reviews 2007;18:CD004565

11. Scott JT, Harmsen M, Prictor MJ, Entwistle VA, Sowden AJ, Watt I. Recordings or summaries of consultations for people with cancer. Cochrane Database of Systematic Reviews 2003;2:CD001539

12. Hacking B, Wallace L, Scott S, Kosmala-Anderson J, Belkora J, McNeill A. Testing the feasibility, acceptability and effectiveness of a 'decision navigation' intervention for early stage prostate cancer patients in Scotland--a randomised controlled trial. Psychooncology 2013;22:1017-24

13. O'Connor AM. User Manual - Decision Self-Efficacy Scale, 1995. Available from: http://decisionaid.ohri.ca/docs/develop/User_Manuals/UM_Decision_SelfEfficacy.pdf. Accessed 5 January 2014

14. O'Connor AM. Validation of a decisional conflict scale. Medical decision making $1995 ; 15: 25-30$

15. O'Connor AM. User Manual - Decision Regret Scale, 1996. Available from: http://decisionaid.ohri.ca/docs/develop/User_Manuals/UM_Regret_Scale.pdf. Accessed 5 January 2014

16. EuroQol Group. EuroQol - a new facility for the measurement of health-related quality of life. Health Policy 1990;16:199-208

17. Gupta S. Intention-to-treat concept: A review. Perspectives in Clinical Research 2011;2:109-112

18. National Institute for Health Care and Excellence. Behaviour Change: Individual Approaches. Nice guidelines [PH49], 2014. Available from: https://www.nice.org.uk/guidance/ph49. Accessed 14 July 2015 
19. Dorresteijn J, Kriegsman D, Assendelft W, Valk G. Patient education for preventing diabetic foot ulceration. Cochrane database of systematic reviews 2010;12:CD001488

20. Waaijman R, Keukenkamp R, de Haart M, Polomski WP, Nollet F, Bus S. Adherence to wearing prescription custom-made footwear in patients with diabetes at high risk for plantar foot ulceration. Diabetes Care, 2013; 36:1613-8.

21. Armstrong D, Lavery L, Kimbriel H, Nixon B, Boulton A. Activity patterns of patients with diabetic foot ulceration. Diabetes Care, 2003; 26:2595-2597

22. Ajzen I. The theory of planned behaviour. Organizational Behavior and Human Decision Processes 1991;50:179-211

23. Przybylski M. Health locus of control theory in diabetes: a worthwhile approach in managing diabetic foot ulcers? Journal of Wound Care 2010;19:228-233

24. Moss-Morris R, Weinman J, Petrie K, Horne R, Cameron L, Buick D. The Revised Illness-Perception Questionnaire (IPQ-R). Psychology and Health 2002;17:1-16

25. Leventhal H, Cameron L. Behavioral theories and the problem of compliance. Patient Education and Counselling 1987;10:117-138

26. Miller W, Rollnick S. Motivational Interviewing: Helping People Change, Third Edition. New York, USA, Guildford Press, 2012 
Table 1 - Decision Navigation (intervention) structure adopted in this study

\begin{tabular}{|c|c|}
\hline \multicolumn{2}{|r|}{ Decision Navigation } \\
\hline $\begin{array}{l}\text { (i) Information } \\
\text { booklet (treatment } \\
\text { decision aid) }\end{array}$ & $\begin{array}{l}\text { Participants received an adapted NHS Scotland information booklet in } \\
\text { the form of a treatment decision aid at baseline, which contained a } \\
\text { breakdown of common treatment options as indicated by the Scottish } \\
\text { Diabetes Foot Action Group. The adapted booklet additionally } \\
\text { contained lists of advantages and disadvantages associated with } \\
\text { different treatment choices, with content collaboratively developed and } \\
\text { approved by the diabetes foot care team at the Edinburgh Royal } \\
\text { Infirmary, NHS Lothian. }\end{array}$ \\
\hline $\begin{array}{l}\text { (ii) Personalised } \\
\text { patient goals }\end{array}$ & $\begin{array}{l}\text { Approximately one week after recruitment, patients received a } \\
\text { telephone call covering a semi-structured interview from a 'Navigator' } \\
\text { (trained assistant psychologist or trainee health psychologist). Further } \\
\text { details on the interview process can be found at www.scoped.org. } \\
\text { Navigators worked collaboratively with the patient to produce a } \\
\text { 'consultation plan', which is an agenda covering the areas for } \\
\text { discussion during the next consultation. This consultation plan was } \\
\text { facilitated by the Navigator but developed, edited and approved by the } \\
\text { patient. The Navigator forwarded the consultation plan to the clinician } \\
\text { in advance of their next scheduled foot appointment. }\end{array}$ \\
\hline (iii) Consultation & $\begin{array}{l}\text { The Navigator accompanied the patient to their scheduled appointment } \\
\text { with the consultant foot care clinician, which was approximately } 2 \\
\text { weeks post recruitment. The Navigator also audio recorded the } \\
\text { consultation and encouraged both the patient and physician to make } \\
\text { use of the consultation plan. }\end{array}$ \\
\hline $\begin{array}{l}\text { (iv) Audio } \\
\text { recording and } \\
\text { written summary }\end{array}$ & $\begin{array}{l}\text { At the end of the consultation appointment, the patient received an } \\
\text { audio copy of the consultation in the form of a compact disc. Post } \\
\text { consultation, the navigator produced a written summary of the main } \\
\text { points discussed in accordance with the questions raised through the } \\
\text { consultation plan. The final version was approved by the consultant } \\
\text { clinician. This written summary was sent to the patient approximately } 3 \\
\text { days after the consultation. }\end{array}$ \\
\hline
\end{tabular}


Table 2 - A summary of outcomes measures.

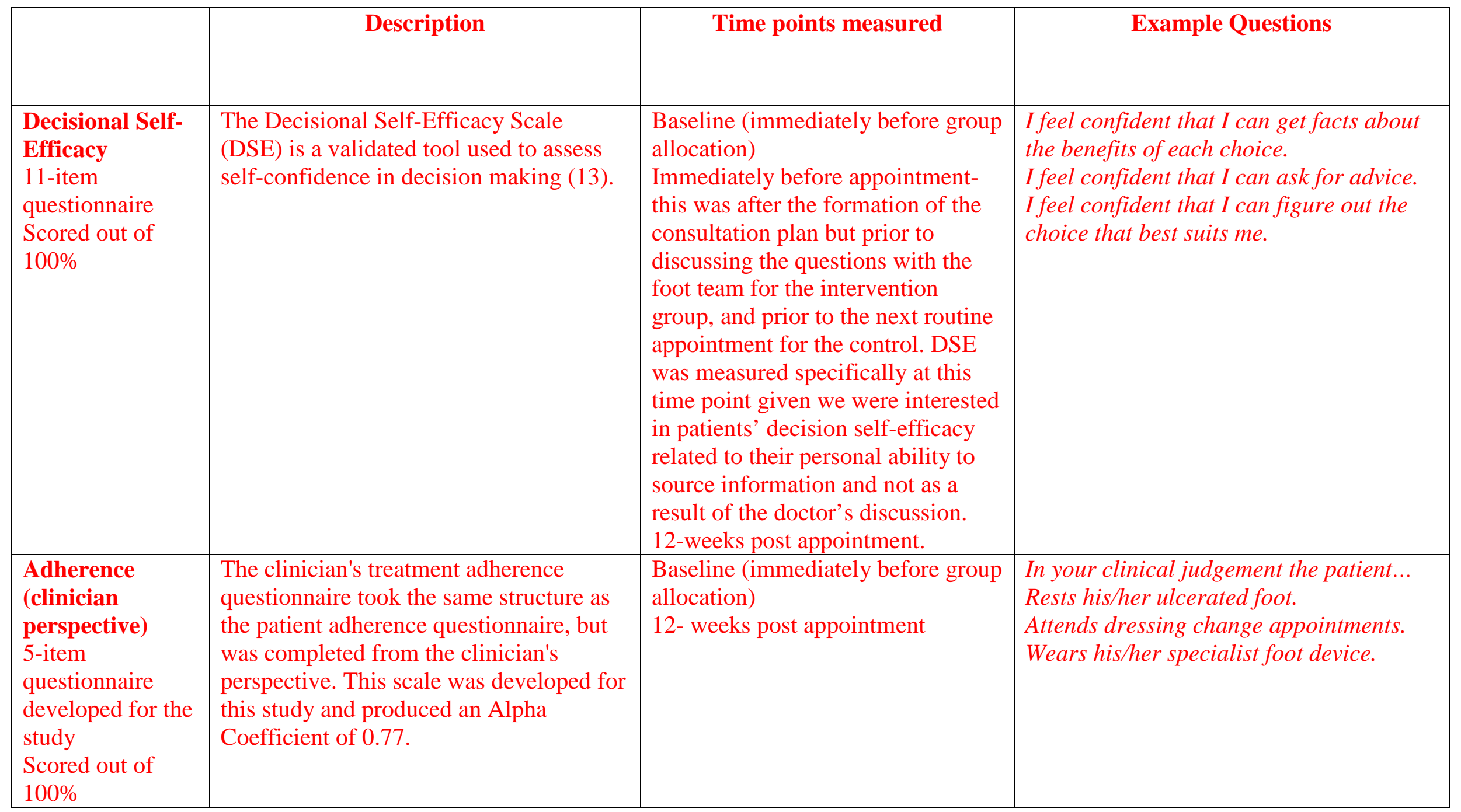




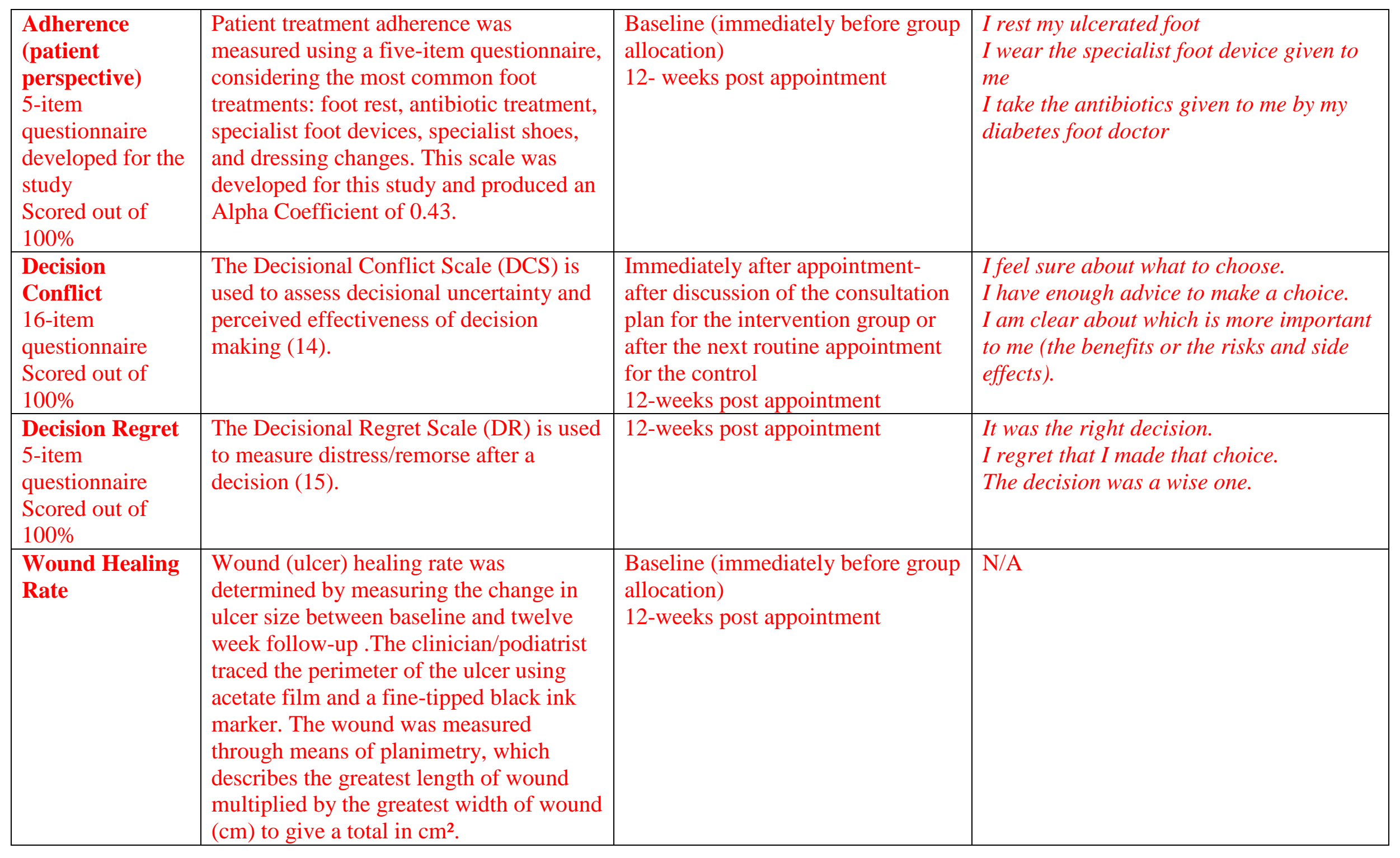




\begin{tabular}{|c|c|c|c|}
\hline & $\begin{array}{l}\text { If more than one ulcer was present, the } \\
\text { same methods were used for each wound } \\
\text { individually and an overall mean healing } \\
\text { rate was calculated and recorded in the } \\
\text { final figures. }\end{array}$ & & \\
\hline $\begin{array}{l}\text { Health-related } \\
\text { Quality of Life }\end{array}$ & $\begin{array}{l}\text { Health-related quality of life was } \\
\text { measured using the European Quality of } \\
\text { Life Scale (EQ-5D) (16). }\end{array}$ & $\begin{array}{l}\text { Baseline (immediately before group } \\
\text { allocation) } \\
\text { 12-weeks post appointment }\end{array}$ & $\begin{array}{l}\text { Under each heading, please tick the ONE } \\
\text { box that best describes your health } \\
\text { TODAY for mobility/ self-care/ usual } \\
\text { acitivites/ pain \& discomfort/ anxiety \& } \\
\text { depression. E.g... } \\
\text { I have severe problems to walk about. } \\
\text { I am able to walk about. }\end{array}$ \\
\hline $\begin{array}{l}\text { Patient } \\
\text { Acceptability of } \\
\text { DN }\end{array}$ & $\begin{array}{l}\text { Patient acceptability of the DN } \\
\text { intervention was measured using a seven- } \\
\text { item self-report questionnaire developed } \\
\text { for this study. It asked participants to rate } \\
\text { each component of the intervention for } \\
\text { helpfulness on a } 10 \text {-point Likert scale } \\
\text { (decision aid; interview with a Navigator; } \\
\text { audio recording; written summary; and } \\
\text { DN overall). It also asked participants to } \\
\text { answer yes/no/unsure to whether they } \\
\text { would opt to using Navigation again and } \\
\text { whether they would recommend it to } \\
\text { another patient with a foot ulcer. } \\
\text { Participants in the intervention group } \\
\text { completed this measure at twelve weeks } \\
\text { post-consultation. }\end{array}$ & 12-weeks post appointment & $\begin{array}{l}\text { How helpful did you find the telephone } \\
\text { call with the Navigator? } \\
\text { How helpful did you find the written } \\
\text { summary of your consultation? } \\
\text { If given the opportunity, would you use } \\
\text { Decision Navigation again in the future? }\end{array}$ \\
\hline
\end{tabular}


Table 3 - Baseline demographics for control and intervention group

\begin{tabular}{|c|c|c|c|}
\hline $\begin{array}{l}\text { Total } \\
(N=56)\end{array}$ & $\begin{array}{l}\text { Control } \\
(N=26) \\
\end{array}$ & $\begin{array}{c}\text { Intervention } \\
(N=30) \\
\end{array}$ & Analyses \\
\hline \multicolumn{4}{|l|}{ Ethnicity } \\
\hline White British & $100 \%$ & $100 \%$ & \\
\hline \multicolumn{4}{|l|}{ Mean Age } \\
\hline Years (SD) & 59.5 (9.9) & 62.5 (14.98) & $F(1,54)=.77, p=.384$ \\
\hline \multicolumn{4}{|l|}{ Employment } \\
\hline Full-time & $23.1 \%$ & $16.7 \%$ & $X^{2}(5, N=56)=4.4$ \\
\hline Part-time & $11.5 \%$ & $3.3 \%$ & $p=.492$ \\
\hline Retired & $46.2 \%$ & $63.3 \%$ & \\
\hline Unemployed & $7.7 \%$ & $13.3 \%$ & \\
\hline Student & $3.8 \%$ & -- & \\
\hline Other & $7.7 \%$ & $3.3 \%$ & \\
\hline \multicolumn{4}{|l|}{ Education } \\
\hline Before 15 & $11.5 \%$ & $20.0 \%$ & $X^{2}(3, N=56)=1.5$ \\
\hline Secondary & $26.9 \%$ & $33.3 \%$ & $p=.682$ \\
\hline College & $26.9 \%$ & $23.3 \%$ & \\
\hline University & $34.6 \%$ & $23.3 \%$ & \\
\hline \multicolumn{4}{|l|}{ Marital status } \\
\hline Married & $53.8 \%$ & $60.0 \%$ & $X^{2}(5, N=56)=3.97$ \\
\hline Partner & $7.7 \%$ & $6.7 \%$ & $p=.554$ \\
\hline Divorced & $7.7 \%$ & $6.7 \%$ & \\
\hline Separated & $3.8 \%$ & $6.7 \%$ & \\
\hline Widowed & $11.5 \%$ & -- & \\
\hline Single & $15.4 \%$ & $20.0 \%$ & \\
\hline Gender (male) & $73.1 \%$ & $73.3 \%$ & $\begin{array}{c}X^{2}(1, N=56)=<.001, \\
p=.983\end{array}$ \\
\hline \multicolumn{4}{|l|}{ Patient status } \\
\hline New & $53.8 \%$ & $63.3 \%$ & $X^{2}(2, N=56)=.9$ \\
\hline Current & $26.9 \%$ & $16.7 \%$ & $p=.637$ \\
\hline Reulcered & $19.2 \%$ & $20.0 \%$ & \\
\hline
\end{tabular}


Table 4 - Summary of primary and secondary completer analyses

\begin{tabular}{|c|c|c|c|c|c|c|}
\hline & $\begin{array}{c}\text { Baseline } \\
\text { (T0) }\end{array}$ & $\begin{array}{c}\text { Next appointment } \\
\text { (T1) }\end{array}$ & $\begin{array}{c}12 \text { weeks } \\
\text { (T2) }\end{array}$ & Group & Time & Group x Time \\
\hline \multicolumn{7}{|l|}{ Decision Self-efficacy } \\
\hline Control $\quad(N=23)$ & 83.03 (19.9) & $81.4(18.46)$ & 86.88 (16.69) & $F=1.39, p=.245$ & $F=6.58, p=.002$ & $F=1.22, p=.299$ \\
\hline Intervention $(N=25)$ & $83.9(13.9)$ & 87.45 (11.33) & $93.18(7.1)$ & $\eta p^{2}=.03$ & $\eta p^{2}=.127$ & $\eta p^{2}=.026$ \\
\hline \multicolumn{7}{|l|}{ Adherence (clinician) } \\
\hline Control $\quad(N=21)$ & $81.75(13.32)$ & -- & $85.13(12.66)$ & $F=3.15, p=.083$ & $F=.86, p=.358$ & $F=.007, p=.934$ \\
\hline Intervention $(N=26)$ & $76.03(17.42)$ & & $79.2(17.16)$ & $\eta p^{2}=.067$ & $\eta p^{2}=.019$ & $\eta \mathrm{p}^{2}=<.001$ \\
\hline \multicolumn{7}{|l|}{ Adherence (patient) } \\
\hline Control $\quad(N=22)$ & $82.13(11.01)$ & -- & 87 (9.36) & $F=.001, p=.976$ & $F=4.8, p=.034$ & $F=.247, p=.622$ \\
\hline Intervention $(N=25)$ & 83.52 (10.68) & & $86.08(9.45)$ & $\eta \mathrm{p}^{2}=<.001$ & $\eta p^{2}=.096$ & $\eta p^{2}=.005$ \\
\hline \multicolumn{7}{|l|}{ Decision Conflict } \\
\hline Control $\quad(N=23)$ & -- & $21.94(18.08)$ & 18.53 (16.07) & $F=.002, p=.962$ & $F=.377, p=.543$ & $F=3.68, p=.049$ \\
\hline Intervention $(N=25)$ & & $17.1(15.17)$ & $23.75(15.34)$ & $\eta p^{2}=<.001$ & $\eta p^{2}=.008$ & $\eta p^{2}=.077$ \\
\hline \multicolumn{7}{|l|}{ Decision Regret } \\
\hline$(N=22)$ & -- & -- & $38.4(17)$ & $F=.242, p=.625$ & -- & -- \\
\hline Intervention $(N=25)$ & & & $40.4(10.3)$ & $\eta p^{2}=.005$ & & \\
\hline \multicolumn{7}{|l|}{ Healing Rate } \\
\hline $\begin{array}{l}\text { Control } \quad(N=20) \\
\text { Intervention }(N=25)\end{array}$ & -- & -- & -- & $\begin{array}{l}\mathrm{F}=.553, \mathrm{p}=.461 \\
\eta \mathrm{p}^{2}=.013\end{array}$ & -- & -- \\
\hline \multicolumn{7}{|c|}{$\begin{array}{l}\text { Health-Related Quality } \\
\text { of Life }\end{array}$} \\
\hline Control & $68.48(22.53)$ & -- & $64.13(23.92)$ & $F=.348, p=.558$ & $F=1.42, p=.24$ & $F=.693, p=.409$ \\
\hline Intervention $(N=26)$ & 70.19 (20.71) & & $69.42(21.28)$ & $\eta p^{2}=.007$ & $\eta p^{2}=.029$ & $\eta p^{2}=.015$ \\
\hline
\end{tabular}

Incomplete or missing data sets were removed from analyses. Mean (Standard Deviation): all scores can be interpreted as percentages. 
Table 5 — Summary of primary and secondary intention-to-treat analyses.

\begin{tabular}{|c|c|c|c|c|c|c|}
\hline & $\begin{array}{l}\text { Baseline } \\
\text { (T0) }\end{array}$ & $\begin{array}{c}\text { Next healthcare } \\
\text { appointment (T1) }\end{array}$ & $\begin{array}{l}12 \text { weeks } \\
\text { (T2) }\end{array}$ & Group & Time & Group x Time \\
\hline \multicolumn{7}{|l|}{ Decision Self-efficacy } \\
\hline Control $\quad(N=26)$ & 83.28 (18.9) & $80.24(20.18)$ & $86.01(15.85)$ & $F=1.23, p=.272$ & $F=5.67, p=.005$ & $F=1.67, p=.194$ \\
\hline Intervention $(N=30)$ & $83.94(17)$ & $87.05(13.86)$ & $91.67(13.52)$ & $\eta p^{2}=.022$ & $\eta p^{2}=.095$ & $\eta p^{2}=.03$ \\
\hline \multicolumn{7}{|l|}{ Adherence (clinician) } \\
\hline Control $\quad(N=23)$ & 81.23 (14.64) & -- & 84.17 (14.28) & $F=2.8, p=.1$ & $F=.86, p=.358$ & $F=.005, p=.945$ \\
\hline Intervention $(N=29)$ & $75.9(16.84)$ & & $78.42(16.94)$ & $\eta p^{2}=.053$ & $\eta p^{2}=.017$ & $\eta p^{2}=<.001$ \\
\hline \multicolumn{7}{|l|}{ Adherence (patient) } \\
\hline Control $\quad(N=26)$ & 83.03 (10.39) & -- & $86.62(9.12)$ & $F=.058, p=.811$ & $F=4.83, p=.032$ & $F=.308, p=.581$ \\
\hline Intervention $(N=30)$ & 83.18 (10.63) & & $85.32(9.83)$ & $\eta p^{2}=.001$ & $\eta p^{2}=.084$ & $\eta p^{2}=.006$ \\
\hline \multicolumn{7}{|l|}{ Decision Conflict } \\
\hline Control $\quad(N=23)$ & -- & $22.21(17.27)$ & $19.09(15.12)$ & $F=.02, p=.887$ & $F=.401, p=.53$ & $F=3.71, p=.048$ \\
\hline Intervention $(N=27)$ & & $18.09(15.19)$ & $24.28(15.08)$ & $\eta p^{2}=<.001$ & $\eta p^{2}=.008$ & $\eta p^{2}=.072$ \\
\hline \multicolumn{7}{|l|}{ Decision Regret } \\
\hline$(N=22)$ & -- & -- & $38.4(17)$ & $F=.242, p=.625$ & -- & -- \\
\hline Intervention $(N=25)$ & & & $40.4(10.3)$ & $\eta p^{2}=.005$ & & \\
\hline \multicolumn{7}{|l|}{ Healing Rate } \\
\hline $\begin{array}{l}\text { Control } \quad(N=24) \\
\text { Intervention }(N=26)\end{array}$ & -- & -- & -- & $\begin{array}{l}\mathrm{F}=.256, \mathrm{p}=.615 \\
\eta \mathrm{p}^{2}=.005\end{array}$ & -- & -- \\
\hline \multicolumn{7}{|l|}{ Health-Related QoL } \\
\hline Control $\quad(N=26)$ & $67.5(21.64)$ & & $63.65(22.78)$ & $F=.528, p=.47$ & $F=1.37, p=.253$ & $F=.792, p=.377$ \\
\hline Intervention $(N=30)$ & 69.67 (20.05) & -- & $69.17(20.05)$ & $\eta p^{2}=.01$ & $\eta p^{2}=.024$ & $\eta p^{2}=.014$ \\
\hline
\end{tabular}

Note. Baseline (last) scores were entered in place of missing data. Mean (Standard Deviation): all scores can be interpreted as percentages. 
